\title{
EXAMINATION OF THE EFFECT OF MELAMINE AS A FILLER IN PAPER COATINGS ON PRINT QUALITY
}

\author{
ARIF OZCAN, ${ }^{*}$ EMINE ARMAN KANDIRMAZ, ${ }^{*}$ PELIN HAYTA** and \\ BEGUM MUTLU*** \\ "Marmara University, School of Applied Sciences, Printing Technologies, 34722 Istanbul, Turkey \\ ${ }^{* *}$ Sinop University, Gerze Vocational High School, Graphic Design Program, \\ 57600 Sinop, Turkey \\ **** Nişantaşı University, Nişantaşı Vocational School, Printing and Publishing Technologies, \\ 34398 Istanbul, Turkey \\ \Corresponding author: Arif Ozcan,arifozcan@marmara.edu.tr
}

Received May 19, 2018

\begin{abstract}
The basic processes applied to provide better printability for paper are surface coating and sizing processes. The desired outcome of these processes is to fill in and compress the rough areas and cavities caused by the fiber structure of the paper. As a result, the paper is enhanced in terms of its optical and physical properties. In this study, the effect of melamine as a coating material on the optical properties of paper was examined. For this purpose, cationic starch sizing and melamine coating processes were carried out on base paper under laboratory conditions and in accordance with appropriate standards. Contact angle, total surface energy and FTIR measurements of the paper were performed according to the standards. Base paper and processed papers were printed with magenta ink by a laboratory type offset printability device. Then, all the samples were subjected to a lightfastness test. CIE L*a* $\mathrm{b}^{*}$, gloss, whiteness and yellowness values of all the samples (base paper, printed, unprinted, surface processed) were determined. As a result, melamine was found to be a suitable filler material for paper coatings, which improves surface properties and increases glossiness.
\end{abstract}

Keywords: CIE L*a*b*, light fastness, melamine, paper coating, sizing

\section{INTRODUCTION}

The paper industry has to increase paper quality due to the increased customer demands and competition. ${ }^{1-5}$ The final quality requirements for paper, when it reaches the hands of the end user, depend on its surface properties. In recent years, the paper industry has focused on improving the paper surface properties. ${ }^{6-7}$ These properties can be improved by mechanical treatments, such as calendaring, and chemical ones, such as sizing and coating. ${ }^{8-10}$ Paper properties, such as glossiness, whiteness, yellowness, CIE L*a*b* color values, porosity, air permeability and surface roughness, play an important role in print quality. ${ }^{11}$ The surface properties of paper depend on the base paper components and surface treatment processes, such as sizing and coating. ${ }^{12-15}$ As a result of such surface treatments, the paper is improved both in terms of physical resistance and optical properties. The significance of improving paper surface properties will be better understood, if we consider that the most important input material in the printing industry is paper. ${ }^{16-17}$

In the sizing procedure, a substance is applied onto the paper to cover its surface irregularities; as a result, the penetration of the ink to be printed on the paper into the bulk of the paper is prevented. This has two advantages: on the one hand, lower ink consumption, and on the other, higher print gloss and optical density can be obtained. ${ }^{18}$ The coating procedure is performed to enhance paper properties, so it can meet higher expectations. This process consists in applying a formulation containing pigments, binders and some additives onto the paper surface. Thus, a smoother surface and better printability properties are obtained. Ink absorption decreases, while gloss increases. ${ }^{19-21}$ The use of starches as a binder is very common due to their low cost and wide availability. ${ }^{22-25}$ The main difference 
between coating and sizing lies in the addition of pigments to the formulation used for coating the paper surface to increase print quality. ${ }^{26-35}$

In cases where the printed sample is exposed to sunlight, such as in the case of outdoor advertising, fading over time is common and damaging to the product functionality. Fading is mostly caused by UV irradiation, but it may be a mistake to attribute fading only to the light. In such cases, it is possible to make predictions by carrying out a lightfastness test. ${ }^{36-38}$

Energy differences between a liquid and the surface of a material are explained by surface energy and surface tension. Molecules repel each other when farther away, and at some in-between distance they neither repel nor attract each other. Inside a liquid, the molecules usually repel each other slightly, just enough to counteract the pressure applied by the surroundings to the liquid. However, the molecules at the surface are farther apart than the neutral distance and therefore they attract each other. This attraction is necessary if surface molecules are to be kept from moving from the surface into the liquid. Wetting explains the flow of a liquid over the material's surface. If wetting is proper, adhesion is strong due to maximum contact. ${ }^{39}$

The contact angle is the angle that a liquid drop deposited on a solid surface makes with the horizontal axis, and it is related to the surface energy of the substrate and the surface tension of the liquid. The contact angle can shed some light on sizing performance. It is the standard test method used to evaluate the wettability of paper surface. ${ }^{40}$

Melamine, a trimer of cyanamide, with a 1,3,5-triazine skeleton, is an organic compound that is an important component of thermosetting coatings. ${ }^{41-42}$ The melamine can be also incorporated into paper during manufacturing to provide more age-resistant paper. ${ }^{43}$

Melamine was widely used in plate marketing, but due to design development, the use of melamine has gradually decreased and the necessity of finding other uses for melamine has arisen.

In this study, melamine was added as filler in paper coating formulations and the effect of melamine addition on the surface properties and the printability of the paper were examined.

\section{EXPERIMENTAL}

In order to analyze the effect of melamine coating on the optical, surface and printability properties of paper, sizing with cationic starch and melamine coating were performed on base paper under laboratory conditions. The parameters of the base paper used in this study are given in Table 1.

Cationic starch-based surface sizing was applied to the base paper. The sizing formulation applied consisted of $7.5 \%$ concentration of cationic starch, which was heated up to $90{ }^{\circ} \mathrm{C}$, and the resulting hotsurface sizing solution was cooled to $60{ }^{\circ} \mathrm{C}$ and then applied onto the paper surface using a Mayer rod number 2 in a laboratory-type paper coating machine. In the second stage of this study, the same preparation process was applied for the paper coating formulation, but $2.7 \%$ melamine was also added to the first mixture. The formulation was applied to the paper surface using the Mayer rod in a laboratory-type paper coating machine under laboratory conditions.

The yellowness and whiteness measurements of unprinted papers were made according to the ASTM E313 standard, where $\mathrm{X}, \mathrm{Y}$ and $\mathrm{Z}$ are the CIE Tristimulus values, and the coefficients depended on the illuminant and observer, as indicated in the standard. The yellowness index could be calculated only for illuminants D65 and C.

Yellowness E313 $=100 \frac{\left(C_{x} X-C_{z} Z\right)}{Y}$

The original, sized and coated papers were printed with Dyoboard DB-5600 Process Magenta commercial offset printing ink, using an IGT C1 offset printability test device, under $400 \mathrm{~N} / \mathrm{m}^{2}$ pressure printing conditions. CIE L*a*b* values of the print results were measured using an X-Rite eXact hand-held spectrophotometer, according to ISO 12647-2:2013, in the spectral range from $400 \mathrm{~nm}$ to $700 \mathrm{~nm}$, under a D50 light source, $2^{\circ}$ observer, polarized filter and 0/45-degree geometry. The color difference formula is given below. Calculations were made by taking the average of five measurements. $\Delta \mathrm{L}^{*}, \Delta \mathrm{a}^{*}, \Delta \mathrm{b}^{*}$ : difference in $\mathrm{L}^{*}, \mathrm{a}^{*}$ and $\mathrm{b}^{*}$ values between the specimen color and the target color. Lightness is represented by the $\mathrm{L}^{*}$ axis, which ranges from white to black. The red area is connected to the green one by the $a^{*}$ axis, while the $b^{*}$ axis runs from yellow to blue.

$\Delta \mathrm{E}=\sqrt{\Delta \mathrm{L}^{2}+\Delta \mathrm{a}^{2}+\Delta \mathrm{b}^{2}}$

Gloss measurements were made with a BYKGardner GmbH glossmeter according to ISO 2813:2014, $60^{\circ}$ geometry. All the printed and unprinted samples were subjected to the lightfastness test in accordance with BS 4321:1969 standard. Following the light aging test, CIE L*a*b*, gloss and yellowness measurements were performed one more time for all the samples.

For the lightfastness evaluation procedure, first of all the CIE L*a*b* color values and gloss of the samples were measured. Then, the printed and unprinted samples were exposed to light aging in a sealed cabinet on a Solarbox 1500 device under 
constant UV light for 192 hours according to BS 43211969 standard. The CIE L*a*b* color and gloss values of the printed and unprinted samples exposed to fading were measured one more time, and the differences between the initial values and the values measured after the lightfastness test were calculated.

Table 1

Parameters of the base paper used in the study

\begin{tabular}{lcc}
\hline Properties & Standard & Paper \\
\hline Grammage $\left(\mathrm{g} / \mathrm{m}^{2}\right)$ & ISO 536 & 80 \\
Thickness $(\mu \mathrm{m})$ & TAPPI T411 & 190 \\
Whiteness $(\mathrm{D} 65 / 10)(\%)$ & ASTM E313 & 99 \\
Gloss $\left(\right.$ TAPPI $\left.60^{\circ} / 75^{\circ}\right)$ & T480 om-92 & 4.9 \\
Yellowness & ASTM E313 & 0.06 \\
\hline
\end{tabular}

Table 2

Total surface energy values according to ASTM D5946

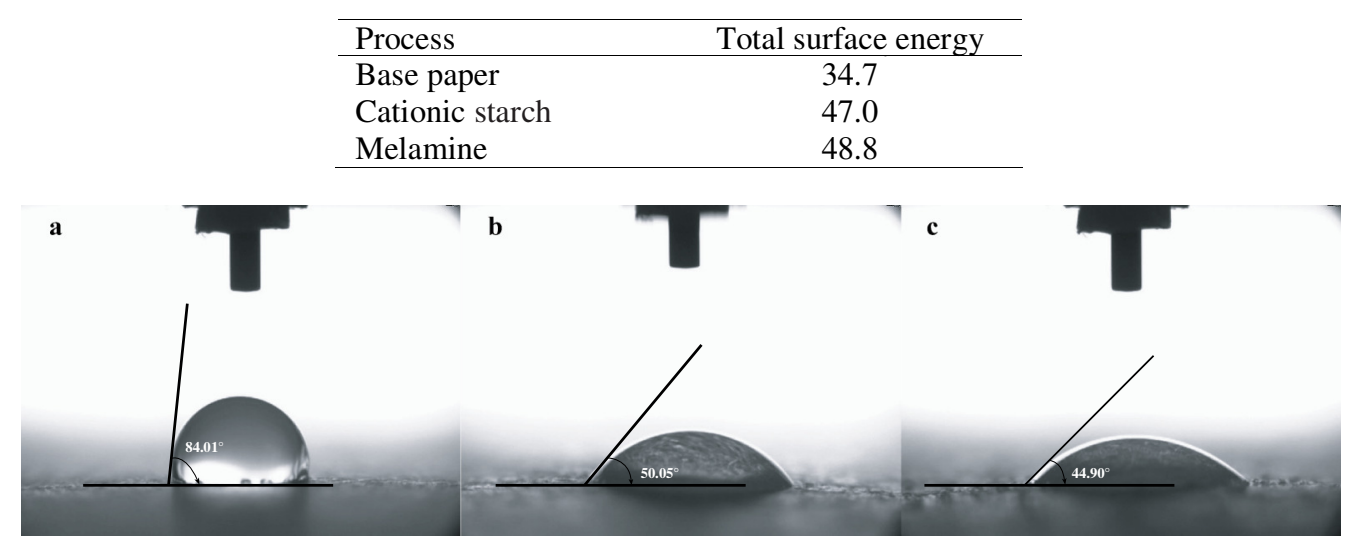

Figure 1: Contact angles of a) base paper, b) cationic starch sized paper, and c) melamine coated paper

The contact angle and total surface energy measurements of the papers were performed by a PocketGoniometer PGX+ in accordance with ASTM D5946 standard. The chemical structures of the base paper, cationic starch sized and melamine coated paper were identified using a Perkin-Elmer Spectrum 100 ATR-FTIR spectrophotometer (WA).

\section{RESULTS AND DISCUSSION}

The total surface energy results (Table 2) indicate that the base paper has the lowest surface energy, while the melamine coated sample has the highest surface energy value. This is most likely due to the hydrogen bonding between melamine and cationic starch. ${ }^{44}$ The surface energy and contact angle values were compatible with each other.

It may be observed from Figure 1 that when the base paper is sized with cationic starch, the surface contact angle is reduced and results in higher wetting. This is because the $-\mathrm{OH}$ groups on the surface of cationic starch cause more hydrogen bonding with water and an increased interaction, that is, an increase in adhesion strength. However, when the contact angle results are examined, it may be noted that the best wetting is achieved on the melamine coated surface. For this reason, besides the hydroxyl groups of cationic starch in the medium, the melamine $-\mathrm{NH}_{2}$ groups increase the amount of hydrogen bonding and generate a higher adhesion force. As the adhesion forces between a material and a water molecule are higher than the cohesive forces of water, the wetting becomes easier and the contact angle is lower. The results are consistent with those reported in the literature. ${ }^{45}$

ATR-FTIR spectra of the paper samples are shown in Figure 2. Figure $2 \mathrm{a}$ reveals the characteristic -OH vibration of cellulose at 3333 $\mathrm{cm}^{-1}$, the symmetric aliphatic $\mathrm{C}-\mathrm{H}$ stretch vibration of methylene at $2898 \mathrm{~cm}^{-1}$, the $\mathrm{C}-\mathrm{O}-\mathrm{H}$ deformation in cellulose at $1025 \mathrm{~cm}^{-1}$ and the aromatic $\mathrm{C}=\mathrm{C}$ stretching vibrations at $1420 \mathrm{~cm}^{-1}$. 
These peaks clearly reveal the chemical structure of the cellulosic paper. The ATR-FTIR results are compatible with those described in the literature. ${ }^{46}$

Figure $2 \mathrm{~b}$ shows that the aromatic $\mathrm{C}=\mathrm{C}$ stretching vibrations at $1420 \mathrm{~cm}^{-1}$ shifted to 1357 $\mathrm{cm}^{-1}$, while the $-\mathrm{OH}$ vibration at $3300 \mathrm{~cm}^{-1}$ intensified. These results are in agreement with those from the literature. ${ }^{47}$ Figure $2 \mathrm{~b}$ supports the chemical structure of cationic starch sized paper. Figure 2c exhibits the spectrum of melamine and cationic starch coated paper. It is clearly observed that the $\mathrm{NH}_{2}$ peak splits into two at $3467 \mathrm{~cm}^{-1}$, while the characteristic - $\mathrm{OH}$ vibration of cellulose and starch is still present in the spectrum. Also, the peak at $1427 \mathrm{~cm}^{-1}$, attributed to C-N stretching of cyclo melamine, and that at $1548 \mathrm{~cm}^{-1}$ corresponding to the side-chain asymmetric C-N stretching and $\mathrm{C}-\mathrm{N}$ ring stretching of melamine indicate the presence of melamine as a filler material in the coating formulations and that it was not decomposed during the reaction. The chemical structure is in consistency with the literature reports. ${ }^{48}$

As shown in Figure 3, the unprinted base paper has a lower gloss value than the coated and sized papers, while the highest gloss value is obtained for the sized paper. The increase in glossiness is directly proportional to the increase in print quality. Surface roughness was reduced upon the addition of the cationic starch used in the sizing process, as it covered the surface of the cellulose fibers, thereby increasing the gloss. The gloss value of the sized papers was higher than that of the base paper. This was an expected result. The paper fibers were fixed with cationic starch, but the presence of melamine in the formulation created some roughness. The result was that the gloss of the coated papers was lower than that of the sized papers. Similar results are also found in the literature. ${ }^{49}$ When the gloss values of the printed papers were examined, it could be concluded that the gloss increased as a function of the pre-print conditions, and the greatest increase in gloss was seen in the paper subjected to melamine coating.

When the gloss values were examined after light exposure (Fig. 4), it was found that all the gloss values were partially reduced due to fading. The greatest gloss reduction was noted for the sized papers, while the gloss value decreased less for the melamine coated papers.

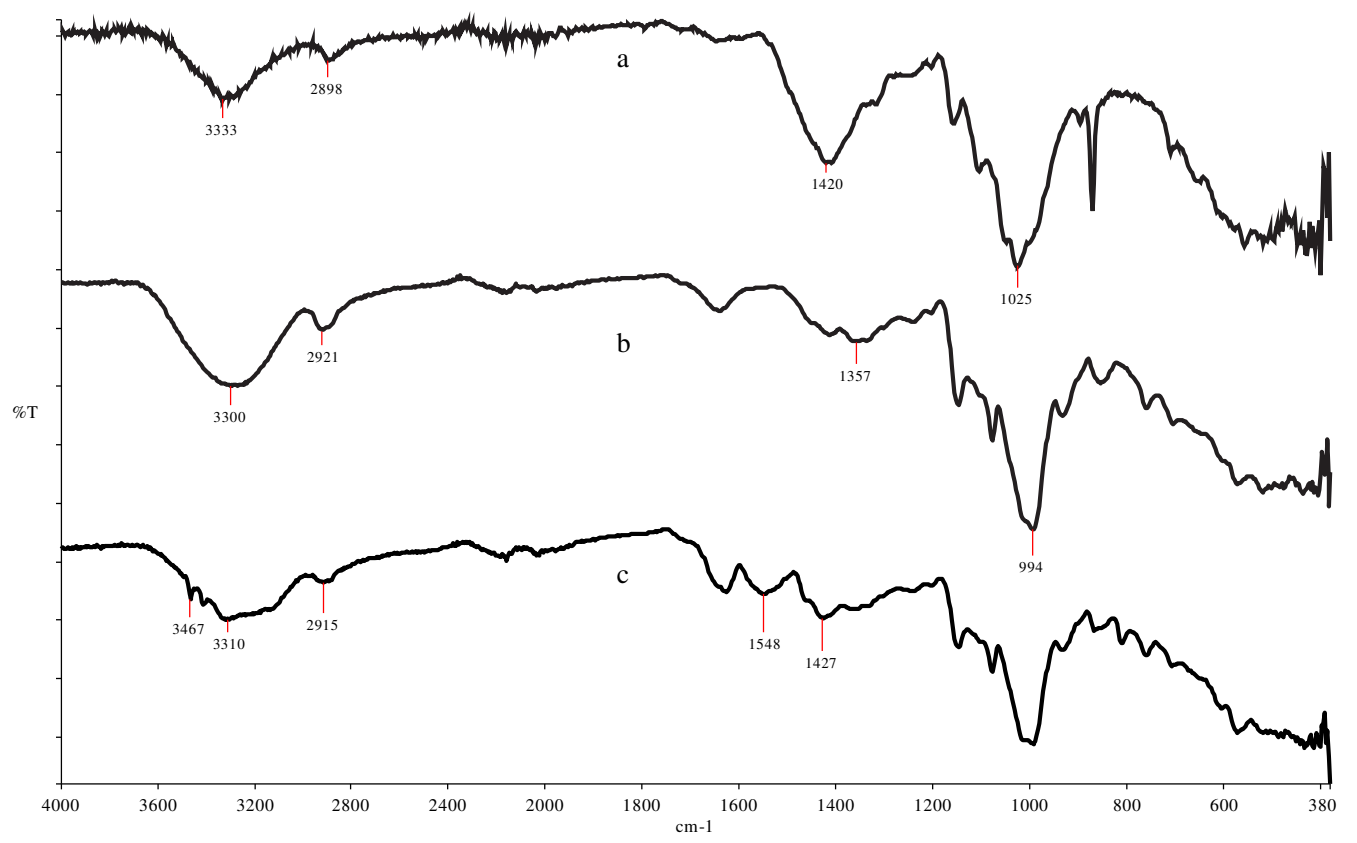

Figure 2: ATR-FTIR spectra of a) base paper, b) cationic starch sized paper, and c) melamine coated paper 


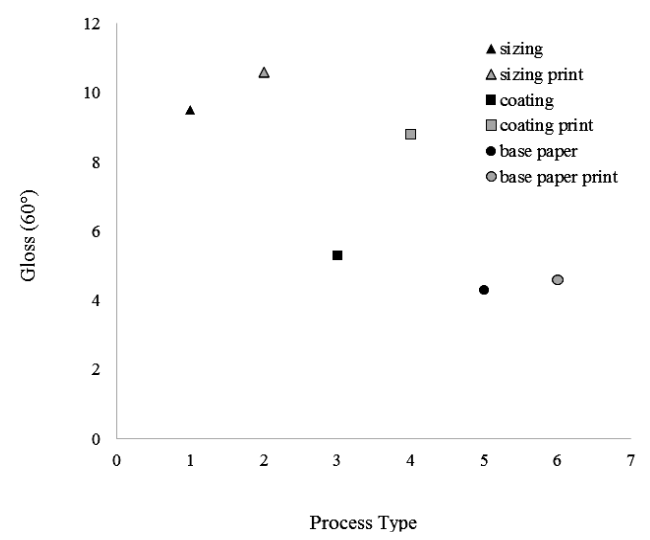

Figure 3: Gloss values before and after printing

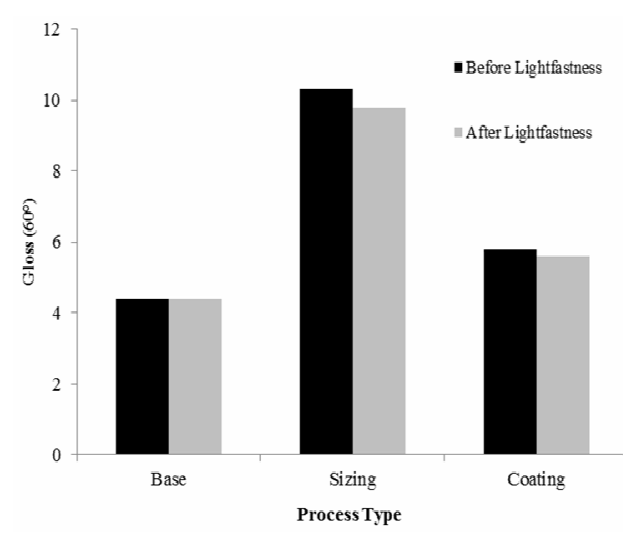

Figure 4: Gloss values after light exposure

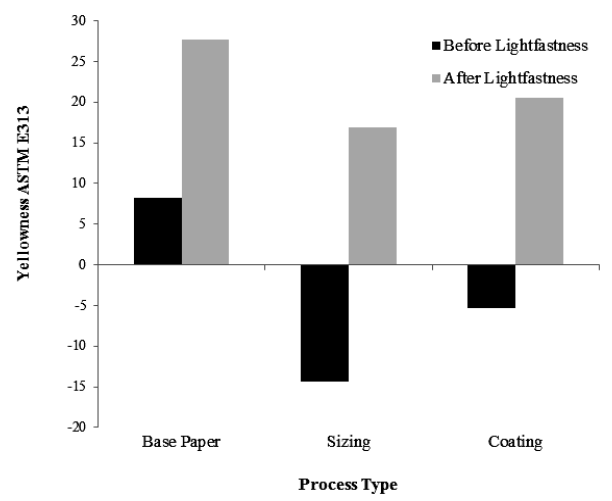

Figure 5: Yellowness values after light exposure of the paper

Table 3

Color difference $\Delta \mathrm{E}$ and $\Delta \mathrm{b}$

\begin{tabular}{lcc}
\hline Sample & $\Delta \mathrm{E}$ & $\Delta \mathrm{b}$ \\
\hline Base paper & 15.8 & 17.72 \\
Sized paper & 14.83 & 16.87 \\
Melamine coated paper & 14.78 & 16.74 \\
Printed base paper & 2.1 & 1.36 \\
Printed sized paper & 2.02 & 3.73 \\
Printed melamine coated paper & 1.82 & 2.18 \\
\hline
\end{tabular}

Table 3 shows that the cationic starch coating reduces the differentiation in color and the addition of melamine makes this reduction even more apparent. The greatest difference between the colors was seen in $\Delta \mathrm{b}$, that is, the yellownessgreenness color characteristic. Unprinted paper clearly turned yellow when exposed to UV light degradation. The results in Table 3 clearly indicate that the coating and sizing procedures can reduce this yellowness value. When the light fastness results of the printed samples were examined, it could be noted that the color difference of the unprinted papers decreased extensively upon printing. When the color differences of the prints were examined among the printed samples only, the largest difference was observed in the untreated paper, while the coating and sizing procedures reduced the color difference. The results were found to be consistent with those reported in the literature. ${ }^{50}$ Based on the results, the greatest $\Delta \mathrm{E}$ component was obtained in $\Delta \mathrm{b}$, that was yellownessgreenness, the colors yellowed after UV light exposure, but the addition of melamine reduced the yellowing of the cationic starch. 
When the yellowness values of the printed samples were examined (Fig. 5), it could be seen that the highest yellowness value was found in the base paper, the yellowness value decreased in the papers treated by sizing and their color shifted towards blue. The addition of melamine reduced this shift. It was found in the light fastness test that the sizing and melamine coatings with negative yellowness values had positive values; the lowest yellowness value was still obtained for the sized papers, while the melamine coating reduced the yellowness value compared to that of the base paper.

\section{CONCLUSION}

The present study allowed drawing the following conclusions.

Cationic starch-based sizing of the paper surface improves the gloss value as it increases surface smoothness. It was found that melamine coating increased the gloss in printed products. Also, exposure to UV light reduces gloss, while the coating with melamine reduces this decrease in gloss.

The study revealed that the surface treatments reduced color changes: yellowing in paper occurs after exposition to light, while the addition of melamine reduces the yellowing on printed paper. When the yellowness values were examined, it was concluded that the value of yellowness decreased for the surface treated papers and the print quality increased.

The highest wetting occurs on melaminecoated surfaces. Thus, printing becomes easier and more effective upon the addition of melamine. As starch sizing increases the amount of hydrogen bonding in the base paper, the starch sized paper presented better wettability than the base paper, while the melamine coating further increased the amount of hydrogen bonding. Thus, the best wettability results were noted for the melamine coated paper. Surface energy and contact angle values were found to be compatible with each other.

The ATR-FTIR analysis confirmed the application of cationic starch sizing and melamine coating onto the cellulose paper. Because the chemical structure of melamine is not changed, it is possible to use it as a filling material in paper coating. Also, it was observed that melamine coating improved the printability parameters of paper and enhanced quality printing.

\section{REFERENCES}

1 Y. Xiang, D. Desjumaux, D. Bousfield and M. F. Forbes, Procs. Pan Pacific and International Printing and Graphic Arts Conference, Quebec, 1998, pp. 85.

2 D. O. Cummings and A. V. Lyons, Procs. TAPPI Coating Conference, Atlanta, 1996, pp. 16.

3 J. S. Preston, N. J. Elton, A. Legrix and C. Nutbeem, Solutions!, 85, 5 (2002).

4 I. M. T. Moutinho, A. M. Kleen, M. M. L. Figueiredo and P. J. T. Ferreirea, Holzforschung, 63, 282 (2009), DOI: https://doi.org/10.1515/HF.2009.046

P. Pruszynski, "WWP Keynote Lectures", 2003, pp. 82-90.

I. M. T. Moutinho, Ph.D. Thesis, Coimbra University, Portugal, 2009.

I. M. T. Moutinho, P. J. T. Ferreira and M. L. F. Figueiredo, Bioresources, 6, 4259 (2011), https://bioresources.cnr.ncsu.edu/BioRes_06/BioRes_0 6_4_4259_Moutinho_FF_Paper_Surf_Chem_Inkjet_Pr int_Quality_1855.pdf

8 R. Carceller and A. Juppo, Pap. Puu-Pap. Tim., 86, 161 (2004).

9 M. Laleg, O Papel/Paprican, 2004, 33 (2004).

10 P. Lertsutthiwong, M. M. Nazhad, S. Chandrkrachang and W. F. Stevens, Apitta J., 57, 274 (2004).

11 P. J. Ferreira, J. A. Gamelas, I. M. Moutinho, A. G. Ferreira, N. Gómez et al., Ind. Eng. Chem. Res., 48, 3867 (2009), DOI: 10.1021/ie801765c.

12 I. Keskitalo, Master's Thesis, Lulea Tekniska Universitet, Sweden, 2000.

13 V. Rutar and A. Hladnik, COST European Action E11 Workshop, Grenoble, France, 2000.

14 J. Oliver, J. Chen and F. Tosto, COST European E11 Meeting, Espoo, Finland, 2001, pp. 1-9.

15 J. P. Koskela and O. E. O. Hormi, Apitta J., 56, 296 (2003).

16 H. K. Navaz, B. Markicevic, A. R. Zand, Y. Sikorski, E. Chan et al., J. Colloid Interface Sci., 325, 440 (2008), https://doi.org/10.1016/j.jcis.2008.04.078,

17 Y. Arai and K. Nojima, Tappi J., 81, 213 (1997).

18 D. W. Donigan, K. J. Wise and J. N. Ishley, Procs. Tappi 1996 Coating Conference, Atlanta, 1996, pp. 39.

19 E. Lehtinen, in "Pigment Coating and Surface Sizing of Paper", Finland, Fapet Oy, 2000, pp. 61-66.

20 E. J. Caner, Master's Theses, University of Toronto, 2006.

21 A. Ozcan, Asian J. Chem., 23, 2755 (2011).

22 R. L. Kearney, Blade Coating Seminar, Tappi Press, Atlanta, 1988, pp. 99.

23 C. Liang, Master's Theses, University of Toronto, 2009.

${ }^{24}$ K. W. Kirby, Procs. Papermakers Conference, Tappi Press, Atlanta, 1985, pp. 59.

25 A. Özcan and Ö. B. Zelzele, MSU J. Sci., 5, 399 (2017), https://dergipark.org.tr/download/articlefile/324272 
26 P. Oittinen and H. Saarelma (Eds.), "Papermaking Science and Technology Encyclopedia”, 1998, vol. 13, Printing.

27 D. W. Donigian, J. N. Ishley and K. J. Wise, Tappi J., 80, 163 (1997).

${ }^{28}$ M. V. H. Nissi, A. Savolainen, M. Talja and M. R. Raija, Tappi J., 82, 252 (1999).

29 S. Lohmander and M. Rigdahl, Nord. Pulp Pap. Res. J., 15, 231 (2000).

30 J. Ahlroos and J. Grön, Tappi J., 84, 68 (2001).

31 P. Fardim and N. Duran, J. Braz. Chem. Soc., 16, $915 \quad$ (2005), http://dx.doi.org/10.1590/S010350532005000600005

32 A. Ozcan, J. Appl. Biomater. Func., 17 (2019), DOI: $10.1177 / 2280800018816012$.

33 U. Forsström, K. Fagerholm and E. Saharenen, Pap. Puи-Pap. Tim., 85, 454 (2003).

34 C. J. Ridgway and P. A. C. Gane, Nord. Pulp Pap. Res. J., 18, 24 (2003), https://doi.org/10.3183/NPPRJ2003-18-01-p024-031

35 G. Engström, in Procs. $13^{\text {th }}$ Fundamental Research Symposium, Cambridge, September, 2005, p. 1011.

36 M. Friskovec, R. Kulcar and M. K. Gunde, Color Technol. 129 , 214

(2013), https://doi.org/10.1111/cote.12020

37 K. Vikman, J. Imag. Sci. Technol., 47, 30 (2003), https://pdfs.semanticscholar.org/bd1f/93b1b6eefd32f3 48c677728438cb7fa2129c.pdf

38 Y. Li, Q. Wang, W. Gu and B. He, in Procs. International Conference on Materials, Environmental and Biological Engineering (MEBE 2015), April, 2015 , pp. 817.
39 S. Fukuda, N. M. Belgacem, D. Chaussy and N. R. Reverdy-Bruas, Cellulose Chem. Technol., 52, 413 (2018),

http://www.cellulosechemtechnol.ro/pdf/CCT56(2018)/p.413-422.pdf

40 P. D. Garrett and K. I. Lee, Tappi J., 81, 198 (1998).

41 T. T. Chang, Prog. Org. Coat., 29, 45 (1996), https://doi.org/10.1016/S0300-9440(96)00645-5

42 N. Sahiner, S. Demirci and K. Sel, J. Porous Mater., $\quad$ 23, $1025 \quad$ (2016), https://doi.org/10.1007/s10934-016-0160-9

43 R. V. Norton, US Patent 4,619,735, 1986.

44 Q. Du, E. Freysz and Y. R. Shen, Science, 264, 826 (1994), DOI: 10.1126/science.264.5160.826

45 A. B. Çiğil, E. A. Kandırmaz, H. Birtane and M. V. Kahraman, Polym. Bull., (2018), DOI: 10.1007/s00289-018-2605-6.

46 M. Schwanninger, J. C. Rodrigues, H. Pereira and B. Hinterstoisser, Vib. Spectrosc., 36, 23 (2004), doi: 10.1016/j.vibspec.2004.02.003

47 S. Pal, D. Mal and R. P. Singh, Carbohyd. Polym., 59 417 (2005), https://doi.org/10.1016/j.carbpol.2004.06.047

48 N. E. Mircescu, M. Oltean, V. Chiș and N. Leopold, Vib. Spectrosc., 62, 165 (2012), https://doi.org/10.1016/j.vibspec.2012.04.008

${ }^{49}$ E. Ural and E. A. Kandirmaz, J. Appl. Biomater. Func., 16, 23 (2018).

50 E. A. Kandirmaz, N. K. Apohan and E. N. Gençoğlu, Prog. Org. Coat., 119, 36 (2018), https://doi.org/10.1016/j.porgcoat.2018.02.012 